\title{
FUNÇÃO MATERNA NO CONTEXTO DA PREMATURIDADE: UMA REVISÃO DA LITERATURA PSICANALÍTICA
}

MATERNAL ROLE IN THE CONTEXT OF PREMATURITY: A REVIEW OF THE PSYCHOANALYTIC LITERATURE

\author{
FUNCIÓN MATERNA EN EL CONTEXTO DE LA PREMATURIDAD: UNA REVISIÓN DE LA \\ LITERATURA PSICOANALÍTICA
}

\author{
Paula de Paula Fernandes* \\ Milena da Rosa Silva*
}

\begin{abstract}
RESUMO
A psicanálise considera a função materna como sendo de extrema importância para o desenvolvimento da criança. No entanto tal função pode se tornar dificultada pelo contexto que envolve o nascimento pré-termo do bebê. O objetivo deste trabalho foi realizar um levantamento da literatura psicanalítica acerca do conceito de função materna e, mais especificamente, sobre as relações entre a função materna e o nascimento pré-termo do bebê. Foram consultados para tanto autores clássicos e contemporâneos. A fim de ilustrar a discussão teórica, o trabalho conta com pequenas vinhetas de dois casos acompanhados em uma UTI neonatal. São elaboradas reflexões sobre como a prematuridade do bebê pode influenciar as primeiras relações entre a díade que se encontra em tal situação. Considera-se que tais perguntas acerca do tema podem ajudar a pensar sobre possíveis intervençóes para que, apesar da condição de prematuridade, mãe e bebê possam se encontrar da melhor forma possível.
\end{abstract}

Palavras-chave: Função materna. Prematuridade. Relação mãe-bebê

\begin{abstract}
Psychoanalysis considers the maternal role as being extremely important for children's development. However, such a role may become troublesome due to the baby's preterm birth condition. This study aims to carry out a review of the psychoanalytic literature on the concept of maternal role, and, more precisely, about the relationship between the maternal role and a baby's preterm birth condition. Both, classic and contemporary authors have been approached in this study. In order to illustrate the theoretical discussion, this study displays short passages from two cases followed in a Neonatal ICU.

Texto recebido em 24 de outubro de 2015 e aprovado para publicação em 20 de setembro de 2016.

* Mestranda em Psicologia no Programa de Pós-Graduação em Psicologia da Universidade Federal do Rio Grande do Sul (UFRGS).E-mail: paulahp_fernandes@hotmail.com.

**Professora no Departamento de Psicanálise e Psicopatologia e do Programa de Pós-Graduação em Psicanálise: Clínica e Cultura, Instituto de Psicologia, UFRGS. E-mail: milenarsilva@hotmail.com.
\end{abstract}


Reflections were brought up about how prematurity may influence the early relations between the mother and the baby who are in such situation. It is considered that these questions about the subject may help to ponder possible interventions that, despite the preterm birth condition, may help mother and baby experience a best level of relationship.

Keywords: Maternal role. Prematurity. Mother-infant relationship.

\section{RESUMEN}

El psicoanálisis considera el papel de la madre como extremadamente importante para el desarrollo del niño. Sin embargo, una función de este tipo puede ser difícil por el contexto del parto prematuro del bebé. El objetivo de este estudio fue revisar la literatura psicoanalítica sobre el concepto de la función materna. Además, revisó al alza sobre los detalles de la relación entre la función materna y parto prematuro del bebé. Fue utilizado ambos autores clásicos y contemporáneos. Con el fin de ilustrar la discusión teórica, la obra tiene pequeñas viñetas de dos casos seguidos en una UCIN. Reflexiones se dibujan sobre como la prematuridad puede influir en la relación temprana entre la madre y el bebé. Se considera que este tipo de preguntas sobre el tema pueden ayudar en posibles intervenciones, y que a pesar de la condición de la prematuridad, la madre y el bebé puedan encontrarse de la mejor manera posible.

Palabras clave: Función materna. Prematuridad. Madre del bebé.

\section{INTRODUÇÃO}

Oonsidera-se que, para a psicanálise, todos os bebês são prematuros, em função da dependência que eles têm em relação a outro ser humano (Oliveira, 2011). O desamparo do bebê ao nascer motiva uma função a ser iniciada pela pessoa que será seu cuidador: a função materna. De acordo com Oliveira (2011), essa função faz com que a pessoa que cuida do bebê tenha a capacidade de traduzir as manifestaçôes orgânicas emitidas pela criança como sendo mensagens de apelo dirigidas ao adulto, que lhes confere um sentido.

A função materna, tomada em seu sentido genérico, tanto pode ser exercida pela mãe propriamente dita quanto por outra pessoa (Zimerman, 1999). Zimerman (2001) destaca que, invariavelmente, os autores de abordagem psicanalítica colocam que a mãe ocupa uma posição central no desenvolvimento emocional da criança.

Devido à importância da função materna para o desenvolvimento psíquico infantil, serão abordadas a seguir as concepções de alguns autores psicanalíticos, 
tanto clássicos quanto contemporâneos, no que diz respeito a tal função.

Stern (1997) coloca que, com o nascimento de uma criança, a mãe passaria por um processo que o autor denomina "constelação da maternidade". Tal processo não se trata de uma condição universal ou inata. Além disso, é uma condição passageira, que pode durar meses ou anos. Segundo o autor, para essa condição, existem influências psíquicas e hormonais, mas principalmente socioculturais. De acordo com ele, a constelação da maternidade é dividida em temas: "vidacrescimento", "relacionar-se primário", "matriz de apoio" e "reorganização da identidade".

Quanto ao tema "vida-crescimento", as questôes centrais giram em torno da capacidade da mãe de manter seu bebê vivo, de permitir que ele se desenvolva. Tais questões provocam na mãe muitos medos, tais como o de que seu bebê morra ou que pare de respirar, podendo levar a mãe a acordar à noite para verificar se seu bebê está respirando, por exemplo. Stern (1997) destaca que essa temática é única no ciclo vital e estaria direcionada às questôes da sobrevivência da espécie.

A temática que trata do "relacionar-se primário" envolve o relacionamento emocional/social da mãe com seu bebê, se esta pode amá-lo ou sentir que este a ama. Tal temática envolve questôes sobre a possibilidade de que a mãe se comunique de forma não verbal e espontânea com seu bebê. $\mathrm{O}$ "relacionar-se primário" também inclui a capacidade de que a mãe possa ler seu bebê, ou seja, compreender seus sinais e necessidades bem como se adaptar a ele e ser capaz de desempenhar o holding.

A "matriz de apoio" envolve o suporte que a mãe deve receber para que possa desempenhar suas funções, que vai desde a proteção ao auxílio. A mãe pode acabar se aproximando mais de figuras femininas do que masculinas, como de sua própria mãe, com quem a relação passa a ser reativada e reorganizada.

Por fim, a temática da "reorganização da identidade" envolve a necessidade da mãe de transformar e reorganizar a sua própria identidade após o nascimento do bebê, pois esta deixa de ser somente filha e esposa para ser também mãe. Para tanto, haverá a busca pelas identificações que teve ao longo de sua história com sua própria mãe e com outras figuras parentais. Há a necessidade de encontrar modelos para desempenhar seu novo papel.

$\mathrm{Na}$ linha de autores que descrevem as relações iniciais da mãe com seu bebê, Lebovici (1987) descreve como "elo mãe-criança" o vínculo que se estabelece entre os dois, possivelmente nas primeiras horas de vida do bebê, após o parto. $\mathrm{O}$ autor cita estudos que tiveram como objetivo investigar a qualidade do elo mãe-criança de acordo com o tempo que a mãe podia passar com o bebê logo 
em suas primeiras horas de vida, tendo visto que quanto maior o tempo que a díade podia passar junto, melhor a qualidade do vínculo observado nos meses seguintes. Assim, o autor relata que os primeiros instantes pós-natais podem ser um período mais sensível para a criação do elo mãe-criança.

Segundo Lebovici (1987), logo após o nascimento, o bebê ainda é um prolongamento de si para a mãe. Além disso, no puerpério, existiria um jogo conflitual por parte da mãe, que estaria relacionado a dois tipos de investimentos: por um lado, a mãe se encontra com seu corpo dolorido, encontra-se fatigada e necessitando de repouso, além de aspirar a uma reflexão sobre ela mesma. Por outro lado, a mãe se sente chamada a dedicar seus cuidados ao seu bebê, que tem fome, chora e tem necessidades vitais. Ao mesmo tempo em que a mãe deve elaborar o luto do bebê imaginário, deve realizar o trabalho psíquico de abrir espaço em sua vida para o recém-nascido. Tais mudanças levam a uma necessidade de reorganização do mundo interno da mãe.

Lebovici (1987) coloca que, devido a esse período em que é necessário que a mãe realize um trabalho de reorganização, é importante que a mãe possa realizar os cuidados do bebê. De acordo com o autor, na ocasião em que essas funções são desempenhadas por outra pessoa (por exemplo, alguém da equipe hospitalar), o aparelho psíquico da mãe seguirá a tendência de limitar seus gastos de energia e a diminuir o trabalho de investimento em tal tarefa. $\mathrm{O}$ autor realça a importância dos momentos iniciais da interação mãe-bebê após o parto e que, dependendo do nível de interação nesse momento, o bebê estará mais ou menos presente na reestruturação pela qual passa a puérpera. Segundo o autor, podem-se observar perturbações do elo mãe-bebê quando tal reestruturação se opera sem a presença do bebê em tal momento, e que se nota isso quando a mãe e o bebê são separados por muito tempo.

Citada por outros autores por ser um conceito muito relevante de sua produção, a "preocupação materna primária" é um estado descrito por Winnicott (2000). $\mathrm{O}$ autor o apresenta como sendo uma identificação, tanto consciente quanto inconsciente, que a mãe tem com o seu bebê. Por outro lado, também há, por parte do bebê, uma dependência em relação à mãe.

Durante tal estado, a mãe apresenta uma sensibilidade exacerbada, que tem início no fim da gestação e duração de algumas semanas ou meses após o parto, e se caracteriza por uma adaptação sensível e delicada da mãe às necessidades do bebê. Ao mesmo tempo, as mães continuam a ser elas mesmas, tendo consciência de uma necessidade de proteção nesse momento em que se encontram vulneráveis. Além disso, as mães assumem também que, dentro de alguns meses, serão capazes de sair dessa situação especial. Segundo Winnicott (2000), é preciso que a mãe 
tenha saúde mental tanto para entrar quanto para sair desse estado.

Winnicott (2006) considera que as mães fazem bem sua função simplesmente pelo fato de que se dedicam à tarefa que têm pela frente, a de cuidar de um bebê. $\mathrm{O}$ autor não idealiza as mães nem as culpabiliza por problemas no desenvolvimento das crianças. No entanto, ao considerar a dedicação algo fundamental, relata que sua ausência não é sem consequências. Segundo o autor, há uma necessidade vital de que o bebê tenha alguém que facilite os estágios iniciais de seu processo de desenvolvimento psicológico, psicossomático ou também da personalidade mais imatura e dependente, que é a personalidade humana. $\mathrm{O}$ bebê precisa de um ambiente de facilitação (que deve ser tanto humano quanto pessoal) e que deve apresentar características suficientemente boas, como a de integração, de ajudar o bebê a se tornar uma unidade, ainda que uma unidade dependente. Dessa forma, "O apoio do ego materno facilita a organização do ego do bebê" (Winnicott, 2006, p. 9).

Essa facilitação a que o bebê encontre uma unidade estaria relacionada à capacidade de holding, ou sustentar, que é o momento em que a mãe sabe como o bebê deve ser manipulado, se deve ser pego no colo ou colocado em alguma superfície (Winnicott, 2006). Segundo o autor, ao longo das repetições desses comportamentos, estes fundamentam a capacidade do bebê de sentir-se real. Segundo Ogden (2010), pelo holding, a mãe protege a continuidade do ser do bebê, sendo que a maturação corresponderia à internalização gradual do holding materno ao longo do tempo. $\mathrm{O}$ autor destaca que, inicialmente, o holding materno proporciona ao bebê que este não sofra os impactos do tempo, impacto este que é absorvido pela mãe. Isso se dá, por exemplo, quando a mãe acorda várias vezes à noite para atender seu bebê, alterando ela o seu ritmo de sono para que o bebê não precise suportar esperar até a "hora certa" de acordar.

Segundo Ogden (2010), a função do holding muda conforme a criança cresce. O holding físico/emocional passa a dar lugar a um holding metafórico, que tem como objetivo promover ao bebê um lugar (que, na verdade, trata-se de um estado psicológico) no qual ele possa se organizar. Aqui, o holding deve promover ao bebê a sensação de sentir-se integrado. De acordo com o autor, tanto as experiências transicionais quanto a capacidade de estar só (que seria a capacidade de estar sozinho na presença da mãe) correspondem à internalização do holding ambiental promovido pela mãe.

Parte importante dessa etapa do desenvolvimento psíquico, de tornar-se um sujeito por si mesmo, é o papel de espelho que caberia à mãe ou à pessoa que exerce a função materna representar. De acordo com Winnicott (1975), o que o bebê vê quando olha para o rosto da mãe é a si mesmo. $\mathrm{O}$ autor destaca a 
importância de que haja uma reação materna à busca do bebê. Quando os bebês têm uma experiência muito longa de não receberem aquilo que estão dando, de olharem e não verem a si mesmos, o que poderia acontecer, segundo o autor, é que a capacidade criativa do bebê poderia atrofiar-se.

Outro autor de destaque no que diz respeito a concepções que abordam o relacionamento mãe-bebê é Bion. De acordo com o autor, a mãe deve ter a capacidade de rêverie, que consiste em ser como um órgão receptor que acolhe as sensações que o bebê experimenta sobre si mesmo, por meio de seu consciente (Bion, 1994). Segundo Zimerman (1995), tal capacidade corresponde a uma condição na qual a mãe está em um estado de "sonho", ou seja, captando o que se passa com o bebê mediante sua intuição. Essa capacidade seria um componente da função-alfa da mãe, que corresponde a fazer uma identificação introjetiva das identificações projetivas do bebê, fazendo ressonância com o que é projetado dentro dela. A continência materna ocorre quando o bebê projeta na mãe suas sensações e esta não somente as acolhe, como também as processa, devolvendoas ao bebê de forma significada. Zimerman (1995) esquematiza os componentes da função de continência da mãe em relação às identificações projetivas do bebê. Seriam estes os de acolher, conter, decodificar, elaborar e devolver tais identificaçōes em doses apropriadas, nomeadas e significadas.

Consideradas as contribuições de autores clássicos da psicanálise, destaca-se que, atualmente, os bebês são vistos como um parceiro ativo na relação com seus pais e com o mundo à sua volta, deixando de ser considerado passivo para tanto (Bernardino, 2008; Dias, 2008). Segundo Bernardino (2008), dessa forma, abre-se o caminho para possibilidades de intervençôes por meios simbólicos, já que os aspectos psíquicos foram se tornando mais relevantes. A autora coloca que o bebê deve realizar a passagem de organismo para sujeito de uma existência simbólica. Isso ocorre a partir de operações psíquicas a serem realizadas mediante uma relação. Esta deve ser sustentada pelos outros parentais (os pais ou aqueles que realizam as funções materna e paterna), que são os transmissores da estrutura simbólica para a criança. Tal transmissão corresponde ao saber inconsciente presente na relação da família com o bebê, passando de geração em geração. Assim, o bebê sustenta as fantasias de continuidade e de imortalidade dois pais. Tece-se em torno do bebê (consciente e inconscientemente) uma rede de expectativas e desejos, que são marcas fundadoras da subjetividade da criança (Battikha, 2008).

\section{PREMATURIDADE}

Quando bebês nascem com menos de 37 semanas de gestação, estes são 
considerados prematuros. Quanto à classificação, os bebês pré-termo são divididos em grupos pela idade gestacional e pelo peso ao nascer. São considerados prétermos extremos aqueles bebês que nascem com idade gestacional inferior a 28 semanas. Muito pré-termos são os bebês que nascem com idade gestacional menor que 28 semanas e até 32 semanas. Pré-termos moderados são considerados os bebês que nascem entre 32 semanas e até 37 semanas gestacionais (WHO, 2012). Quanto ao peso, os bebês são classificados como extremamente baixopeso quando nascem com menos de $1000 \mathrm{~g}$. Bebês que nascem com menos de 1500 g são considerados muito baixo-peso (Cloherty, Eichenwald, \& Stark, 2011).

Segundo Silveira et al. (2010), a prematuridade é a maior causa de morte neonatal, sendo um problema de saúde global que afeta tanto os países ricos quanto os pobres. De acordo com Silveira et al.(2008), 61,4\% das causas perinatais de morte infantil no Brasil estão associadas ao parto prematuro, e geralmente em decorrência de problemas respiratórios. $\mathrm{O}$ baixo-peso ao nascer $(<2500 \mathrm{~g})$ também é uma das maiores causas de mortalidade infantil, sendo que os bebês que sobrevivem têm maior incidência de problemas neurológicos (Barros, Victora, Matijasevich, Santos, Horta, Silveira \& Barros, 2008).

No Brasil, de 2000 para 2010, houve um aumento na proporção de nascimentos pré-termo de $6,7 \%$ para $7,1 \%$, ocorrendo um maior aumento relativo nas regiōes Sul e Sudeste. Além disso, observou-se ainda um aumento no nascimento de bebês com peso abaixo de $2500 \mathrm{~g}$ (Brasil, 2011).

Em relação aos fatores de risco associados à prematuridade, autores apontam para o baixo-peso materno antes da gestação e ganho de peso materno insuficiente durante a gravidez, extremos de idade materna, histórico de natimorto, tabagismo materno durante a gravidez, sangramento vaginal, infecção do trato geniturinário e hipertensão arterial materna (Barros et al., 2008; Silveira et al., 2008). A hipertensão gestacional e a pré-eclâmpsia são disfunçōes hipertensivas que ocorrem a partir de 20 semanas gestacionais, acontecendo em $2 \%$ a $7 \%$ das gestações a nível mundial (Branch, Karumanchi, Yu, \& Zhang, 2012). Segundo Souza, Araújo e Costa (2011), no Brasil, cerca de 10\% das gestações evoluem para o alto risco, e as Síndromes Hipertensivas Gestacionais (SHG) acabam se tornando a principal causa de morte fetal e materna. Tais síndromes apresentam diversificados sintomas clínicos, e as causas ainda representam um importante ponto de discussão no meio científico. Dessa forma, a prematuridade acaba se tornando uma das mais frequentes complicações das SHG, devido ao decorrente trabalho de parto espontâneo ou à conduta obstétrica de interrupção da gravidez.

Segundo pesquisas, questôes sociais podem se tornar fatores de risco para 
o parto prematuro. Entre eles estão a baixa escolaridade materna, trabalho informal, número de consultas pré-natais inferior a cinco, renda familiar baixa e ausência de um parceiro (Silveira et al., 2008; Silveira et al., 2010). O aumento do uso da reprodução assistida também é um elemento a ser levado em conta em relação ao aumento do número de nascimentos pré-termo, pois o uso de tais técnicas aumenta a chance de gestações múltiplas, e a gestação gemelar também é um fator de risco para a prematuridade (Tucker \& McGuire, 2006).

Quanto aos fatores emocionais ligados ao parto prematuro, o estresse materno é apontado como fator de risco para o nascimento pré-termo do bebê (Barros et al., 2008; Silveira et al., 2008; Silveira et al., 2010). Rondó et al. (2003) afirmaram que aspectos psicológicos maternos podem estar relacionados com o peso do bebê ao nascer e à idade gestacional, podendo ser considerados agravantes para o nascimento pré-termo e baixo peso ao nascer.

Autores apontam que é provável que o nascimento prematuro do bebê, em muitos casos, seja ocasionado por fatores múltiplos, já que a prematuridade pode ter fatores clínicos, sociais e emocionais associados (Barros et al., 2008; Tucker \& McGuire, 2006).

\section{A CONSTITUIÇÃO DO SUJEITO NO CONTEXTO DA PREMATURIDADE}

Em relação ao que foi já exposto, podemos considerar que a função materna é de extrema importância para o desenvolvimento inicial e subsequente do bebê. Quanto ao tema da prematuridade, podemos inferir que essa é uma importante questão de saúde pública atual. Conforme a medicina foi avançando, muitos bebês que antes não sobreviveriam agora têm uma chance maior de sobreviver, ainda que, para alguns deles, isso não ocorra sem alguma consequência para seu desenvolvimento.

Segundo Battikha (2008), a estrutura simbólica é transmitida para a criança a partir do saber inconsciente que perpassa a relação do bebê com seus cuidadores. Bernardino (2008) ressalta que é quando esse saber inconsciente falha que a clínica psicanalítica com bebês encontra lugar. Tal capacidade esperada nessas relações pode romper-se em algumas situações, nas quais quem exerce as funçôes paterna e materna para o bebê não consegue realizar a função de representantes do Outro para ele. Entre os fatores que podem levar a isto, a autora cita acidentes do acaso e acidentes simbólicos. A autora destaca que situações como a do nascimento pré-termo do bebê poderiam fazer com que este se tornasse menos responsivo aos investimentos dos pais, podendo ser considerado este um acidente do acaso. 
Segundo Krodi (2008), os pais dos bebês que nascem em situações nas quais se faz necessária uma internação em um ambiente hospitalar neonatal ficam diante não somente do desamparo que é comum à condição humana, mas também do desamparo que é vivido por seus filhos nesse momento. Assim, faz ressurgir a experiência dos próprios pais como bebês desamparados. Entretanto, de acordo com a autora, seria esse desamparo que possibilitaria à mãe identificar-se com o seu bebê.

O que pode dificultar essa identificação, muitas vezes, diz respeito à condição em que o bebê se encontra naquele momento. Krodi (2008) ressalta que os procedimentos e aparelhos da unidade de terapia intensiva (UTI) neonatal acabam por fazer com que os pais se sintam impedidos de se aproximarem de seu bebê, tanto física quanto psiquicamente. Reconhecer seus traços no bebê e investir libidinalmente neste também pode se tornar difícil em algumas situações, pois o bebê tende a ser muito diferente do bebê imaginado. Há sempre um luto a ser realizado após o nascimento do bebê real, mas este pode se tornar intensificado ou impossibilitado em casos em que o bebê precise permanecer sob cuidados em uma UTI neonatal.

De modo semelhante, Mathelin (1999) destacou que, além da elaboração do luto comum a todo o nascimento, também é necessário elaborar, no caso de nascimentos pré-termo, o luto da perda e da separação precoce. A autora destacou que é indispensável que o bebê tome forma não apenas no ventre da mãe, mas também em seu fantasma, e isso ocorre, muitas vezes, nos últimos meses de gravidez. São justamente os meses finais de gestação que não chegam a acontecer, devido a nascimentos prematuros extremos. Esses meses, além de serem importantes para a construção do bebê no psiquismo materno, são valiosos também para que a gestante passe a ser reconhecida pelas pessoas mais próximas como futura mãe.

No entanto, de acordo com Mathelin (1999), quase sempre é a violência que precede o nascimento de um bebê prematuro. Muitas vezes, a decisão médica é tomada em meio à urgência, para salvar a mãe e, ou, o bebê. Assim, o bebê pode nascer já em meio ao pânico e ao imprevisto. A autora aponta que pode haver um desencontro entre a mãe e o bebê: o bebê pode estar muito fraco e distante, e não dar à mãe o sentimento de que está interessado nela. Já foram comentadas as colocações de Stern (1997) a respeito da temática do relacionar-se primário, em que o autor aponta para a importância de que a mãe possa não somente amar seu bebê, mas também de sentir que este a ama. Se isso não é possível, segundo Mathelin (1999), o investimento e o amor entre eles podem se tornar problemático, havendo o risco de que o bebê não tenha nada em que se agarrar para poder constituir-se. 
Assim, os pais de bebês internados em UTI neonatal são atravessados pela instabilidade e pela imprevisibilidade e, alguns deles, pelo perigo de morte de seu bebê (Krodi, 2008). Dessa forma, os pais podem entrar em um estado de angústia automática, no qual podem ter dificuldades de nomear o que sentem e, além disso, a sua angústia pode ligar-se a significantes, como a sensação de não ser bem atendido no hospital e de não ser considerado responsável e participante nas decisões sobre o tratamento do bebê. A autora aponta que a angústia pode estar ligada especificamente ao saber técnico e, muitas vezes, é a dificuldade de olhar e de responder sobre seu filho prematuro que coloca o psiquismo e as defesas dos pais em ação. Nesse sentido, Esteves (2009) aponta como dificuldades possíveis de serem enfrentadas pelas mães na situação de nascimento prematuro do bebê "a preocupação da mãe com a sobrevivência do filho e com a sua própria vida; o distanciamento inicial imposto à díade; a frustração por não poder amamentar logo; a delegação de cuidados à equipe neonatal; a vulnerabilidade do bebê; a culpa por não ter conseguido levar a gestação a termo; e as dificuldades em decifrar os sinais e as dificuldades do bebê" (p. 162).

De acordo com Bernardino (2008), Winnicott foi um dos primeiros autores a se referir à questão da prevenção em saúde mental. Segundo o autor, as bases da saúde mental seriam estabelecidas pelo "ambiente facilitador", atribuído à figura materna. A prevenção se coloca necessária quando o ambiente não consegue realizar a sua função de facilitador. Aqui, a autora considera que o conceito de "ambiente", de Winnicott, pode ser uma extensão do conceito de Outro, de Lacan. Segundo Winnicott (2000), há o ambiente não suficientemente bom para o bebê, que distorce o desenvolvimento deste, e o ambiente suficientemente bom, normalmente referido na figura da mãe suficientemente boa, que possibilita que o bebê alcance as satisfações pertinentes a cada etapa. É necessário que esse ambiente facilitador, na fase mais primitiva do desenvolvimento da criança, capacite o bebê a começar a existir, a ter experiências, constituir um ego pessoal, e a defrontar-se com as dificuldades inerentes à vida (Winnicott, 2000). Winnicott afirma que tudo parece simples quando as coisas vão bem, que a base de tudo se encontra nos primórdios do relacionamento, quando mãe e bebê estão em harmonia. Mathelin (1999) retoma as colocações de Winnicott a respeito da entrada da mãe no estado de preocupação materna primária, e o fato de que o autor aponta que é necessário que a mãe esteja em boa saúde para poder atingi-lo. A partir disso, Mathelin questiona, diante de todas as angústias que envolvem o nascimento pré-termo do bebê, como a mãe pode estar em bom estado. Segundo a autora, as mães, ao estarem próximas a incubadoras, podem acabar sofrendo de uma incapacidade de pensar sobre o seu bebê. "O que ele sente?" (Mathelin, 1999, p. 70). Dessa forma, tais mães acabariam presas na 
armadilha de quem sabe melhor sobre seu filho são os médicos e não elas.

Segundo Bernardino (2008), quando a função de facilitador falha, "Rompese a capacidade dos pais de intermediarem a relação do bebê com seu corpo, seu psiquismo e seu lugar de falante" (p. 25). O que colabora para a situação de risco psíquico para o bebê (como no caso de internação hospitalar devido ao nascimento prematuro deste) é uma possível fragmentação do bebê diante de diferentes olhares, com diferentes equipes técnicas, médicas e diferentes especialidades. De acordo com a autora, em tais casos, é necessário ajudar os pais a restabelecerem a sua transferência com a criança, a fim de que o ambiente possa tornar-se facilitador novamente, bem como sustentar o eixo da singularidade do bebê diante dos diversos olhares. Além disso, é necessário sustentar o eixo da subjetividade suposta do bebê, pela consideração do desejo e da capacidade do brincar nos contatos cotidianos com os pais e com os integrantes das equipes técnicas que lidam com o bebê. Assim, torna-se fundamental que os pais consigam acionar o seu saber inconsciente sobre o bebê, autorizando-se a supor ali um sujeito, e reconstituindo os laços familiares possivelmente rompidos pela situação inesperada que os envolveu.

Com o objetivo de ilustrar uma experiência de contato com as díades de mãe-bebê prematuro, resgataram-se fragmentos de casos acompanhados em um período de um estágio de Psicologia realizado em uma UTI neonatal de um hospital da rede pública de Porto Alegre. Ressalta-se que aqui são expostas apenas pequenas vinhetas, com o objetivo de ilustrar as reflexões a partir da literatura, e não de realizar uma compreensão dos casos.

\subsection{Gabrielle e Violeta}

Gabrielle nasceu prematura, com 32 semanas de gestação, mas já estava se recuperando bem. Seus pulmões já estavam melhores do que na data do nascimento, e ela já podia respirar sozinha. Seu peso também já estava quase chegando aos $2000 \mathrm{~g}$, e, assim, logo ela sairia da incubadora e poderia ser colocada em um berço. Um dia, cheguei para falar com sua mãe, Violeta, para saber como estavam as coisas. Ela me respondeu, muito chateada, que não queria conversar com ninguém naquele dia e começou a chorar. Acabou me contando, no corredor da unidade, o que aconteceu. Disse que estava tudo muito bem com Gabrielle outro dia, quando a estava visitando, e que logo ela sairia da incubadora. Disse que uma das técnicas de enfermagem foi pegá-la para trocála. Quando Violeta foi entregar Gabrielle para a técnica, sentiu que as mãos da técnica estavam muito geladas. $\mathrm{Na}$ troca, disse que a técnica encostou as mãos nas costas da bebê. Disse ter comentado: "Nossa, mas a tia está com a mão muito 
gelada pra encostar em mim”, e que a funcionária não lhe dera ouvidos. Quando conversava comigo, Violeta contou, muito chateada, que Gabrielle pegara um resfriado e somente poderia sair da incubadora quando parasse de tomar a medicação para curá-lo. Disse que sabia que foi por causa das mãos geladas da técnica que seu bebê ficou doente.

\subsection{Brenda e Rosa}

Na primeira vez que conversei com Rosa em atendimento, esta disse ser uma pessoa muito frágil e angustiada. Disse que não gostava de doença e que, quando alguém da família ficava doente, ela se afastava, não gostava de aproximar-se muito, ficava com medo. Relatou esse tipo de sentimento diante da situação de internação da filha, e que foi muito difícil ver Brenda pela primeira vez na incubadora, entubada. Brenda era um bebê pré-termo extremo, extremamente baixo-peso. Parte da dificuldade de ver seu bebê naquela situação perpassava o fato de que Rosa dizia saber que, de alguma forma, Brenda estava sentindo dor. Ainda durante aquela época, Rosa ficava pouco tempo quando ia visitar a filha no hospital, e sempre ia acompanhada. Ao longo do tempo de acompanhamento, Rosa passou a ir sozinha e a poder passar mais tempo com a filha junto à incubadora. Quando Rosa passou a poder segurar Brenda no colo, depois de já terem se passado diversos meses de internação, a mãe preferia pegar a filha quando esta estava mais agitada, para não a agitar quando ela já estava calma, e para não provocar quedas de saturação no bebê. Durante um tempo, Rosa dizia que procurava pegá-la no colo um pouco de manhã e um pouco de tarde, para que a filha não se sentisse mal quando fosse colocada de volta na incubadora, e para que não sentisse tanto sua falta quando ela fosse embora, pois tais sentimentos eram percebidos por Rosa nela mesma.

A partir dos recortes, podemos observar que há vias possíveis de identificação materna com seu bebê, ainda que este esteja hospitalizado. A fragilidade de Violeta ao expor o que havia acontecido mostra que esta poderia estar identificada com seu bebê (que, naquele momento, encontrava-se igualmente frágil). Além disso, as mães se autorizavam a saber sobre o seu bebê (no caso de Violeta), valorizando o seu saber mais do que o saber técnico. No entanto é necessário considerar também que, muitas vezes, os pais que se encontram em situações desse tipo podem acabar realizando projeções na equipe, como aponta Krodi (2008). Além disso, também de acordo com a autora, a angústia dos pais pode ligar-se especificamente ao saber técnico.

A sensibilidade demonstrada por Rosa, ao dizer que sabia que a filha sentia dor, é trazida por Winnicott (2000) como sendo característica da "preocupação 
materna primária” bem como a adaptação da mãe ao seu bebê, quando Rosa decide que poderia retirar a filha da incubadora e segurá-la no colo nos momentos que ela considerava que fossem melhores para o seu bebê. A outra fala de Rosa, em que disse tentar fazer com que a filha Brenda não sentisse tanto sua ausência quando ela tinha de ir embora do hospital no fim do dia, parece uma tentativa de holding por parte da mãe, na qual esta tentava fazer com que o bebê não sofresse tanto os impactos do tempo, protegendo-o e buscando promover um mínimo de sentimento de continuidade ao seu bebê (Ogden, 2010; Winnicott, 2006).

Como já foi comentado, Stern (1997) coloca que uma das temáticas presentes na "constelação da maternidade" é a temática de "vida-crescimento", na qual a mãe se preocupa com a sobrevivência de seu bebê. O medo da morte de seu bebê cerca todas as mães, às quais, como exemplifica o autor, podem acordar à noite para verificar se a criança está respirando. No entanto, em casos de prematuridade do bebê, tal sentimento pode se tornar exacerbado, devido ao risco real de morte do bebê.

Com base em pesquisa qualitativa realizada mediante entrevistas com mães de bebês prematuros, Esteves (2009) afirmou que o estado de "preocupação materna primária" referido por Winnicott também se apresenta no contexto da prematuridade, ainda que seja uma experiência que é marcada pela condição do bebê. A autora refere que o nascimento pré-termo do bebê acaba por exigir mais participação da mãe nos cuidados do bebê, o que pode, inclusive, exacerbar a formação da "preocupação materna primária" em algumas mães.

\section{CONSIDERAÇÕES FINAIS}

A literatura vem destacando as dificuldades presentes na interação entre a díade mãe e bebê pré-termo. No entanto, de acordo com Esteves (2009), alguns fatores positivos podem se sobressair em meio a tais dificuldades, como a construção simbólica do lugar do filho, a qual, em alguns casos, não havia sido feita durante a gestação; a identificação materna, depois dos primeiros contatos; a realização da mãe com os cuidados do filho; a sensibilidade frente às necessidades do bebê; e a percepção da dependência dos bebês dos cuidados e da presença materna. De forma geral, a autora conclui que os achados de seu estudo apontam para uma aproximação suficientemente boa das mães com os filhos nos momentos iniciais.

Por outro lado, Oliveira (2011) considera que a prematuridade pode ser um obstáculo para a função materna. A autora considera como parte para a causa de possíveis dificuldades a homogenia do conhecimento tecnológico e organicista que estão presentes nesse contexto. Dessa forma, a autora atenta para necessidade de que as mães reconheçam o seu direito de poder realizar a sua função com o 
seu bebê. Em estudo realizado por Oliveira (2011), ela apontou que, em casos de nascimento pré-termo do bebê, é necessário um tempo maior para inscrição e a elaboração dos pais (e especialmente da mãe) para decifrar seu bebê. A autora aponta para a importância da atenção aos pais para que os bebês não acabem existindo para estes apenas no que diz respeito ao trauma que pode representar tais nascimentos.

Retomando as considerações de Lebovici (1987) acerca dos momentos iniciais da relação entre mãe-bebê, o autor coloca que o desenvolvimento do que ele chama de "elo mãe-criança" se dá logo nas primeiras horas de interação entre a díade, sendo a qualidade da formação desse elo essencial para a relação posterior entre a mãe e o bebê. Segundo o autor, o ideal é que a mãe possa ocupar-se dos cuidados do recém-nascido para que este possa fazer parte da reestruturação psíquica pela qual a mãe deve passar após o parto. Mesmo que o bebê esteja internado em uma UTI neonatal e que, portanto, seus cuidados tenham de ser realizados pela equipe hospitalar, é necessário, portanto, fazer com que a mãe participe desses cuidados da forma que seja possível, de acordo com as condições de seu bebê. É importante, como assegura Mathelin (1999), que a equipe do hospital não se torne uma grande mãe para aquele bebê que, de fato, já tem a sua.

A equipe, inicialmente, realiza um papel de terceiro na relação da mãe com seu bebê e, no entanto, sua tarefa posteriormente acaba por ser aproximar a díade, permitir que mãe e filho possam se encontram em meio a tantas diversidades. Nesse sentido, assim como a mãe tem a função de significar para o bebê elementos que o seu psiquismo não pode dar conta (Bion, 1994), em casos de prematuridade do bebê e consequente internação em UTI neonatal, a mãe pode entrar em um estado em que também é necessária significação de algo que, muitas vezes, não se pode dar conta sozinho (Mathelin, 1999). Dessa forma, é preciso um auxílio por parte da equipe que acompanha esse tempo, para que os pais superem os momentos de angústia iniciais e possam ver seu bebê além da incubadora e dos tubos.

Em suma, como aponta Winnicott (2006), a função materna é simples, porém de extrema importância. Muitas vezes, as mães podem exercê-la sem maiores problemas e sem necessitarem de intervenções. Entretanto, situações como as de prematuridade podem se mostrar como um elemento que dificulta as primeiras relações das mães com seus bebês. Dessa forma, torna-se importante refletir sobre o impacto que o nascimento pré-termo do bebê pode ter na função materna. Ainda assim, como apontam os estudos revisados e, principalmente, as vinhetas selecionadas de acompanhamentos realizados em UTI neonatal, notase que, apesar das dificuldades que representam o momento de parto prematuro, 
as mães podem conseguir encontrar estratégias para exercer a função materna com seu bebê, ainda que no contexto hospitalar. 


\section{REFERÊNCIAS}

Barros, F. C., Victora, C. G., Matijasevich, A., Santos, I. S., Horta, B. L., Silveira, M. F., \& Barros, A. J. D. (2008). Preterm births, low birth weight, and intrauterine growth restriction in three birth cohorts in Southern Brazil: 1982, 1993 and 2004. Caderno de Saúde Pública, 24, S390-S398.

Battikha, E. C. (2008). A inscrição do estranho no familiar. In M. C. M. Kupfer \& D. Teperman (Orgs.), O que os bebês provocam nos psicanalistas. (pp. 135146). São Paulo: Escuta.

Bernardino, L. M. F. (2008). É possível uma clínica psicanalítica com bebês? In M. C. M. Kupfer \& D. Teperman (Orgs.), O que os bebês provocam nos psicanalistas. (pp. 13-30). São Paulo: Escuta.

Bion, W. (1994). Estudos psicanalíticos revisitados. São Paulo: Imago.

Brasil. Ministério da Saúde. (2011). Atenção à saúde do recém-nascido: guia para os profissionais de saúde. Brasília: Ministério da Saúde, Secretaria de Atenção à Saúde, Departamento de Ações Programáticas e Estratégicas. (Séria A. Normas e Manuais Técnicas, 4). Recuperado a partir de http://bvsms.saude.gov.br/bvs/ publicacoes/atencao_recem_nascido_\%20guia_profissionais_saude_v4.pdf

Cloherty, J. P., Eichenwald, E. C., \& Stark, A. R. (2011). Manual de neonatologia. Rio de Janeiro: Guanabara Koogan.

Dias, M. M. (2008). Progressos da ciência, destinos do sujeito. In M. C. M. Kupfer \& D. Teperman (Orgs.), O que os bebês provocam nos psicanalistas. (pp. 71-84). São Paulo: Escuta.

Esteves, C. M. (2009). A preocupação materna primária em mães de bebês nascidos pré-termo. (Dissertação de Mestrado). Universidade Federal do Rio Grande do Sul, Programa de Pós-Graduação em Psicologia, Instituto de Psicologia, Porto Alegre.

Krodi, P. (2008). Cuidados paliativos em neonatologia: à escuta do indizível. In M. C. M. Kupfer \& D. Teperman (Orgs.), O que os bebês provocam nos psicanalistas. (pp. 115-134). São Paulo: Escuta.

Lebovici, S. (1987). A constituição do elo entre a mãe e o recém-nascido (pp. 115-126). O bebê, a mãe e o psicanalista. Porto alegre: Artes Médicas.

Mathelin, C. (1999). O sorriso da Gioconda. Rio de Janeiro: Companhia de 
Freud.

Ogden, T. H. (2010). Esta arte da psicanálise: sonhando sonhos não sonhados e gritos interrompidos. Porto Alegre: Artmed.

Oliveira. M. G. (2011). Função maternal e a constituição subjetiva na condição de prematuridade. (Dissertação de Mestrado). Universidade Federal do Pará, Programa de Pós-Graduação em Psicologia, Belém.

Rondó, P. H. C., Ferreira, R. F., Nogueira, F., Ribeiro, M. C. N., Lobert, H., \& Artes, R. (2003). Maternal psychological stress and distress as predictors of low birth weight, prematurity and intrauterine growth retardation. European Journal of Clinical Nutrition, 57, 266-272.

Silveira, M. F., Santos, I. S., Barros, A. J. D., Matijasevich, A. Barros, F. C. \& Victora, C. G. (2008). Aumento da prematuridade no Brasil: revisão de estudos de base populacional. Revista de Saúde Pública, 42(5), 957-964.

Silveira, M. F., Victora, C. G., Barros, A. J. D., Santos, I. S., Matijasevich, A., $\&$ Barros, F. C. (2010). Determinants of preterm birth: Pelotas, Rio Grande do Sul State, Brazil, 2004 birth cohort. Caderno de Saúde Pública, 26(1), 185194.

Souza N. L., Araújo, A. C. P. F., \& Costa, I. C. C. (2011). Significados atribuídos por puérperas às síndromes hipertensivas da gravidez e nascimento prematuro. Revista da Escola de Enfermagem da USP, 45(6), 1285-1292.

Stern, D. N. (1997). A constelação da maternidade. In D. N. Stern. A constelação da maternidade: panorama das psicoterapias pais/bebê. (pp. 161-178). Porto Alegre: Artes médicas.

Tucker, J. \& McGuire, W. (2006). ABC of preterm birth: epidemiology of preterm birth. BMJ, 329(18), 675-678.

World Health Organization. (2012). Born too soon: the global action report on preterm birth. Geneve: WHO. Recuperado a partir de https://www.who.int/ pmnch/media/news/2012/201204_borntoosoon-report.pdf

Winnicott, D. W. (1975). O brincar e a realidade. Rio de Janeiro: Imago.

Winnicott, D. W. (2000). Da pediatria à psicanálise: obras escolhidas. Rio de Janeiro: Imago. 
Winnicott, D. W. (2006). Os bebês e suas mães. Rio de Janeiro: Imago.

Yu, X. D., Branch, D. W., Karumanchi, D. A., \& Zhang, J. (2012). Preeclampsia and retinopathy of prematurity in preterm births. Pediatrcis, 130(1), 101-109.

Zimerman, D. E. (1995). Bion: da teoria à prática: uma leitura didática. Porto Alegre: Artes Médicas.

Zimerman, D. E. (1999). Fundamentos psicanaliticos: teoria, técnica e clínica. Porto Alegre: Artes Médicas.

Zimerman, D. E. (2001). Vocabulário contemporâneo da psicanálise. Porto Alegre: Artmed. 